\title{
MÄRCHEN AUS DEM MÄRCHENHAFTEN \\ MAGYARENLAND. DAS UNGARNBILD IN MAILÁTHS \\ MÄRCHENSAMMLUNG MAGYARISCHE SAGEN UND \\ MÄHRCHEN (BRÜNN, 1825) ${ }^{1}$
}

\author{
ORSOLYA LÉNÁRT \\ Lehrstuhl für Kulturwissenschaften, Andrássy Universität Budapest \\ orsolya.lenart@andrassyuni.hu
}

\begin{abstract}
Die vorliegende Studie beschäftigt sich mit der Märchensammlung einer deutsch-ungarischen Vermittlerfigur: Graf Johann Mailáth (1786-1855). Mailáth erfüllte nämlich mit seiner Anthologie eine mehrfache Brückenfunktion: Einerseits transferierte er durch seine Erzählungen ein positives, dem Geschmack der Romantik entsprechendes Bild über das Königreich Ungarn. Andererseits wollte er durch seine Märchen, die auch ins Ungarische übersetzt worden sind, eine neue Gattung in der ungarischen Literatur einbürgern. Die Autorin des vorliegenden Aufsatzes versucht hier, die Bedeutung der Magyarischen Sagen und Mährchen hinsichtlich literaturhistorischer Entwicklungen des deutschen und ungarischen Sprachraumes sichtbar zu machen und die darin vermittelten Ungarnbilder im historischen Kontext zu analysieren.
\end{abstract}

Schlüsselwörter: Ungarnbild, Imagologie, Kulturtransfer, Märchenforschung, ungarische Literatur, deutschsprachige Literatur

\section{Einleitende Gedanken - Graf Mailáth als Kulturvermittler}

Graf Johann Mailáth (1786-1855), ungarischer Adeliger und deutscher Schriftsteller, ${ }^{1}$ wie er in manchen literaturhistorischen Abhandlungen erwähnt wurde, galt neben Georg Gaal und Alois Mednyánszky nicht nur als ein Mitglied des Wiener Kreises des Freiherren Hormayr und der Wiener Trias der ungarischen Märchenforschung, ${ }^{2}$ sondern er war auch einer der erfolgreichsten Werber für die ungarische Kultur und Literatur im deutschsprachigen Ausland. Als seine literarische Karriere ihren Anfang nahm, konzentrierte sich der Graf, geprägt u.a. von Friedrich Schlegel, auf altdeutsche Sprachdenkmäler, die in der Bibliothek der Kalocsaer Domkapitel von Martin Kovachich entdeckt wurden. ${ }^{3}$ Nachdem der Plan, die Kalocsaer Handschriften zusammen mit Johann Paul Köffinger in drei kommentierten Bänden herauszugeben, nur zum Teil realisiert werden konnte, ${ }^{4}$ 
wandte sich Mailáth der ungarischen Literatur zu. Aller Wahrscheinlichkeit nach beeinflusste ihn dabei Ferenc Kazinczy, der „Doyen der ungarischen Literatur“5 zur Zeit der Aufklärung. In diesen Jahren hat der Graf, der mit der deutschen Sprache aufwuchs, den Versuch unternommen, auf Ungarisch zu dichten. ${ }^{6}$ Trotz ermutigender Worte Kazinczys, mit dem er seit 1817 dank Hormayr in regem Briefwechsel stand, musste er jedoch erkennen, dass seine Ungarischkenntnisse für die Poesie nicht geeignet waren. Von nun an setzte er sich zum Ziel, durch Übersetzungen die deutschsprachige Leserschaft auf das ungarische Kultur-, Literatur- und Märchengut aufmerksam zu machen.

1825 war es soweit, dass er neben einer eigenen Anthologie (Gedichte, Wien, 1825) eine Sammlung Magyarischer Gedichte (Stuttgart, 1825) und Magyarischer Sagen und Mährchen (Brünn, 1825) 7 in Druck geben konnte. Die drei Anthologien, insbesondere die Märchensammlung, die im Mittelpunkt der vorliegenden Studie steht, ernteten sowohl in Ungarn, als auch im deutschen Sprachraum schöne Erfolge: In- und Ausländische Zeitschriften (wie die Wiener Theaterzeitung ${ }^{8}$ und die Tudományos Gyüjtemény) ${ }^{9}$ rezensierten eifrig den Band mit zwölf Märchen. Sie wurden, manche bereits vor ihrer Veröffentlichung im Märchenband, in unterschiedlichen, namhaften Almanachen (wie im Archiv für Geschichte, Statistik, Literatur und Kunst ${ }^{10}$ oder Muzárion $)^{11}$ veröffentlicht. Aufgrund dieses positiven Widerhalls einerseits und wegen Mailáths Funktion als kultureller Vermittler andererseits stellt sich die Frage: Was für ein Ungarnbild hat er mit den Sagen vermittelt? In seiner Märchensammlung transferierte er nämlich nicht nur den ungarischen Märchenschatz in deutsche Sprache, sondern er adaptierte diese Texte und setzte sie teils in neue Kontexte. Ein Beispiel: Mailáth bearbeitete neben ungarischen Volkssagen auch bekannte Märchen aus der Sammlung der Brüder Grimm, wie z.B. die Geschichte von Schneewittchen. Mailáth hat sie dann in einer Sage über einen Bruderzwist integriert, und dabei nutzte er als Fassade der Darstellung der märchenhaften Vorkommnisse das Königreich Ungarn, insbesondere die Regionen Ober- und Niederungarn sowie Maramarosch.

Nach einem kurzen Überblick über die Lage und Entwicklung der Märchenforschung in Ungarn, an der sich neben Mailáth die oben erwähnten Gaal und Mednyánszky ebenfalls beteiligten, widmet sich die Verfasserin den folgenden Fragen: Wie sind die Ungarnbilder in den Mailáth'schen Märchen zu klassifizieren? Auf welche literarischen und historischen Wurzeln lassen sie sich zurückführen? Eine Ausgangsthese lautet demzufolge, dass die seit dem Mittelalter in der deutschsprachigen Literatur kursierenden Ungarn-Topoi (wie etwa ,fertilitas Hungariae/Pannoniae' oder , propugnaculum Christianitatis') in der ersten Hälfte des 19. Jahrhunderts durch Deutsch-schreibende Hungari weiter tradiert wurden. Dank ihrer Vermittlertätigkeit wurden dann diese literarischen Images vom ungarischen Volk ,sich einverleibt' und avancierten schließlich zu Bauteilen seines Eigenbildes. 


\section{Zum Sammeln und Erforschen von Märchen in Ungarn in der ersten Hälfte des 19. Jahrhunderts und zur Rolle des Grafen Johann Mailáth}

Wie allgemein bekannt, suchten die deutschen Autoren in der Epoche der Romantik, einem durchaus chaotischen Zeitalter, neue Orientierungspunkte. Sie fanden diese in der Gattung des Märchens und des Volksliedes, die als Repräsentationen der Kindheit galten und ein Stadium der Ursprünglichkeit der Nation verkörperten. Gleichzeitig begann die Sammlung dieser Ausprägungen der sogenannten ,Urpoesie“: Archim von Arnim und Clemens Brentano sammelten Volkslieder (Des Knaben Wunderhorn, 3 Bde., Heidelberg/Frankfurt 1806-1808), die Brüder Grimm veröffentlichten 1812 ihre Kinder- und Hausmärchen, sowie 1816 die Deutschen Sagen, die laut Inge Stephan als ,patriotische Dokumente gegen die nationale Zersplitterung “" gedacht waren. $^{12}$

Die Stilrichtung der Romantik fand bald außerhalb des Deutschen Bundes einen intensiven Widerhall. Beispielsweise auch im Königreich Ungarn, das die Aufmerksamkeit der deutschen Romantiker, die sich um die Entdeckung der deutschen Vergangenheit bemühten, bald auf sich zog. Die Idee der Romantik fand in der sich erneuernden ungarischen Literatur ${ }^{13}$ bald Nachfolger und ihre Verbreitung wurde nicht nur durch den intensiven Briefverkehr der deutschen Romantiker mit den ungarischen Literaten, sondern auch durch die Präsenz v.a. Friedrich Schlegels in Pest und Ofen vorangetrieben. Als Schlegel 1808 mit seiner Frau nach Wien zog und sich dort in den Dienst der antinapoleonischen Politik stellte, musste er nach dem Fall Wiens erst nach Pest und später nach Ofen ziehen, wo sich übrigens auch ein Teil des Wiener Hofes aufhielt. Während seines Aufenthaltes in Ungarn lernte er den Herausgeber und Gelehrten Ludwig Schedius kennen, dessen Haus als Treffpunkt für deutschsprachige Autoren galt. Seine Gesellschaft suchten übrigens neben Schlegel auch der Dramatiker Joseph Collin und der Tiroler Freiheitskämpfer Freiherr Joseph von Hormayr. Neben Friedrich Schlegel pflegten aber auch Jakob Grimm und Gustav Büsching Kontakte zu ungarischen Gelehrten, vor allem aber zu Schedius und zum Bibliothekar Martin Kovachich. Im Mittelpunkt ihres Interesses stand - im Kontext der Erforschung des Nibelungenliedes - die Frage, ob jene Märchen in Ungarn bekannt waren, die das Leben von Attila thematisierten. ${ }^{14}$

Aus der Sicht der ungarischen (und generell der mitteleuropäischen) Folkloreforschung galt aber die Schrift von Jakob Grimm aus 1815 mit dem Titel Cirkular wegen Aufsammlung der Volkspoesie ${ }^{15}$ als eine ,Stunde Null'. ${ }^{16}$ Grimm forderte seine Leser dazu auf, ihm allerlei Volkslieder und Volksmärchen zukommen zu lassen. Damit gab er laut Voigt einen bedeutenden Impuls für das Sammeln von volkstümlichen Texten nicht nur in der ungarischen, sondern auch in der serbischen und rumänischen Sprache. Obwohl aus dem Briefwechsel der Brüder 
Grimm nicht hervorgeht, mit wem sie in Ungarn in Verbindung waren, ${ }^{17}$ darf man annehmen, dass ungarische Gelehrte obigem Schreiben nach begannen, sich mit dem ungarischen Volksmärchenschatz intensiver zu beschäftigen. Wie Zoltán Újváry anmerkte: Das 19. Jahrhundert war in Ungarn die Zeit des Übergangs vom instinktiven Interesse für die Volksmärchen zur bewussten Sammeltätigkeit und Erforschung des ungarischen Märchenschatzes, was sich eng mit der Frage der ungarischen Sprache verknüpfte. ${ }^{18}$

Es ist aber auch kein Zufall, dass sich jene Schriftsteller (Gaal und Mailáth) für die Vermittlung des ungarischen Märchenschatzes einsetzten, die in Wien als Mitarbeiter des Freiherrn Hormayr galten. Während die deutschen Romantiker in den Märchen das ,Zementierungsmittel' für die zersplitterte deutsche Nation entdeckten, galten die v.a. von Gaal, Mailáth und Mednyánszky gelieferten Märchen aus den Kronländern der Monarchie für Hormayr als Bausteine seines habsburgpatriotischen, ,gesamtmonarchistischen' Diskurses. Etwas später, im 22. Band seines Taschenbuchs für vaterländische Geschichte, in dem 1841 eine neue Rubrik mit dem Titel Sagen und Legenden, Zeichen und Wunder gestartet wurde, erklärte er, warum ihm diese Gattung besonders am Herzen lag:

„Ein Volk, dessen Vorzeit in Lied und Sage, in Buch und Bildern
stets das großartige Bewußtsein einflößt, [...]dessen Geschichte
durch und durch Dichtung, wenn auch nirgend Erdichtung ist,
ein solches Volk [...] vielleicht wird es doch überwunden, aber
unterjocht wird es nie. " ${ }^{19}$

Es war kein Zufall, dass im Kreis des Freiherrn das Sammeln von Märchen der Völker der Monarchie zu einer Tradition wurde. ${ }^{20}$ Mednyánszky startete 1820 im Taschenbuch eine Rubrik mit dem Titel Sagen und Legenden, ${ }^{21}$ deren Texte er später in einem eigenen Band unter dem Titel Erzählungen, Sagen und Legenden aus Ungarns Vorzeit (Pest, 1829) herausgab. Aus der Sicht der Entwicklung der ungarischen Märchenforschung war jedoch die Sammlung Georg Gaals von größerer Bedeutung. Wie es der bedeutende Literaturkritiker und -historiker des ungarischen Reformzeitalters, Ferenc Toldy (geb. Schedel), formulierte: Gaal war überhaupt der „erste Entdecker der ungarischen Märchenwelt.“222

Gaals Sammlung mit 17 Märchen erschien 1822 in Wien unter dem Titel Märchen der Magyaren. Der Band war wohl eine Auswahl aus Gaals Sammlung, denn bis 1860 wurden insgesamt 80 Märchen unter dem Namen Gaals veröffentlicht. Die Forschung geht, in Anlehnung an Toldy, ${ }^{23}$ der aus Verwandtschaftsgründen gute Beziehungen zu Gaal pflegte, ${ }^{24}$ davon aus, dass Gaal beim Sammeln des ungarischen Märchenschatzes von den Brüdern Grimm und ihren Ausgaben geprägt wurde. $\mathrm{Ob}$ es eine Kontaktaufnahme zwischen den Grimms und Gaal gab, kann zurzeit nicht beantwortet werden, da sich aus dem Briefwechsel der Brüder 
nicht erschließen lässt, mit wem sie in ihrer Wiener Zeit verkehrten. Es steht jedoch fest, dass die Grimms die Ausgabe Gaals (wie auch Mailáths) kannten und auf sie in der dritten Ausgabe der Kinder- und Hausmärchen Bezug nahmen. ${ }^{25}$

Im Kontext des vorliegenden Aufsatzes ist es aber relevanter, dass Gaals Sammeltätigkeit auch unmittelbar auf seinen Kollegen, Graf Johann Mailáth, eine Wirkung ausüben konnte. Es fällt auf, dass Mailáth bereits 1821 ein Märchen (Willi Tanz) in der Wiener Zeitschrift ${ }^{26}$ veröffentlichte, das dann in seiner 1825 veröffentlichten Sammlung als ,Aufmacher' erschien, auch in weiteren Periodika verlegt wurde, sowie mehrere Bearbeitungen (z.B. von Theresa Artner) und sogar eine ungarische Übersetzung erlebte. ${ }^{27}$ Neben Gaal könnte das dritte Mitglied der Wiener Märchen-Trias, Alois Mednyánszky, Einfluss auf den Grafen gehabt haben. Diese Annahme wird laut Ujváry durch die Tatsache untermauert, dass Mailáth sich bei der Bearbeitung der Legende von Péter Szapáry ${ }^{28}$ auf den Text von Mednyánszky ${ }^{29}$ stützte. ${ }^{30}$ Aber auch bei der Bearbeitung der Legende von Der Eingemauerte wich Mailáth nur in geringem Ausmaß von der Erzählung Mednyánszkys ${ }^{31} \mathrm{ab}$.

Im Vergleich zu den Sammlungen Gaals und Mednyánszkys fällt jedoch bei Mailáth auf, dass seine historischen Forschungen und Archivaufenthalte maßgeblich seinen Zugang zum volkstümlichen Stoff beeinflussten. Von den in der ersten Ausgabe der Sammlung vermittelten Texten gehören eigentlich nur vier (Die Königstöchter, Die Brüder, Eisen Laczi, Zauberhelene) zur Gattung ,,Volksmärchen" im engsten Sinne, die anderen sind Bearbeitungen historischer Stoffe. ${ }^{32}$ Die Sagen und Märchen lebten im Volksmund wahrscheinlich nicht in der Form, in der man sie bei Mailáth lesen kann. Denken wir nur an manche komplizierte Namen im Märchen Königstöchter (Capellidoro, Blanchetta, Nerabella, Fanferina usw.). Die unterschiedlichen volkstümlichen Motive und historischen Stoffe verwandelte Mailáth dank seiner Phantasie und seines schriftstellerischen Geschicks in literarische Novellen und Erzählungen im Stil E. T. A. Hoffmans und Ludwig Tiecks. ${ }^{33}$

\section{Erzählungen über das an Gold reiche Königreich und über dessen kampferprobte und -bereite Bewohner}

Die Tatsache, dass Mailáth als Kulisse für seine Märchen das Königreich Ungarn verwendete, bzw. dass er Stoffe der ungarischen Geschichte bearbeitete, mag die Volksmärchenforschung bedauern. Dass somit ungarische Orte und Persönlichkeiten den Rahmen für die Märchen Mailáths gaben, eröffnet umgekehrt den Komparatisten die Möglichkeit, seine Erzählungen als Quellen zur Erschließung von Eigen- und Fremdbildern zu betrachten. Bevor man mit der konkreten Analyse der Texte beginnt, muss einiges über die Mechanismen der literarischen 
Images (der ,Eigen- und Fremdbilder') im Generellen und über das Ungarnbild ,ungarndeutscher' Autoren in den ersten Jahrzehnten des 19. Jahrhunderts im Speziellen geklärt werden.

Das Königreich Ungarn als Thema fand aufgrund des jahrhundertelangen Mitund Nebeneinanders Eingang in die literarischen Texte des deutschen Sprachraumes. Bereits in den frühen deutschen Textdenkmälern, wie etwa im Hildebrandslied, erschien das Bild ,Ungarns', und diese literarischen Bilder entfalteten sich dann weiter. Für die Natur dieser Fremdbilder, oder mit den Termini der imagologischen ${ }^{34}$ und xenologischen ${ }^{35}$ Forschung, Imagotypen'/,Stereotypen', ist charakteristisch, dass sie besonders zäh sind, sich nur langsam verändern, aber doch der Wandelbarkeit ausgesetzt sind. Das Aufkommen der literarischen Fremdbilder ist Ergebnis von interkulturellen Austauschprozessen und hängt stark mit dem historischen (oder auch politischen) Umfeld der daran Beteiligten zusammen. Obwohl imagotype Elemente sich also langsam verändern, ist laut Tünde Radek genau ihr Wandel im Verlauf der Zeit ein wichtiger Charakterzug. ${ }^{36}$ Es muss zugleich auch angemerkt werden, dass das Fremdbild nicht ohne ein Eigenbild existieren kann. Ihre Kooperation weist auch darauf hin, dass Bilder über das kulturell Andere nie ,in Stein gemeißelt' sind und ihre Beurteilung auch mit der Positionierung des Eigenen eng zusammenhängt. ${ }^{37}$

Die Frage nach dem Eigenen und Fremden ist im Kontext Deutsch-schreibender Hungari der ersten Hälfte des 19. Jahrhunderts besonders spannend. Die Aussage, dass Fremdbilder nie homogen sind und sich als ,Puzzles' aus verschiedenen Bausteinen zusammensetzen, gilt insbesondere für jene Autoren, die in der Epoche der Aufklärung und der aufkommenden Romantik tätig waren. Ihr Ungarnbild hängt nämlich einerseits mit ihrem spezifischen Heimat-Verständnis, das in der Forschung als Hungarus-Patriotismus ${ }^{38}$ bezeichnet wird, andererseits aber auch mit der Zusammensetzung des ungarländischen Deutschtums, das aus mehreren historischen Schichten bestand, eng zusammen. Im Königreich Ungarn lebten um 1800 Deutsche, deren Ahnen teils schon mit den Ostsiedlungsbewegungen nach Ungarn gekommen waren, während andere sich erst während der josephinischen Administration (vorwiegend in den Zentren Pest und Ofen) niederließen. Dazu kam, dass jener (ungarisch-stämmige) Adel einen Teil der deutschsprachigen Intelligenz ausmachte, der schon von seiner Erziehung her deutschsprachig war und dessen Identität laut Tarnói durch österreichische oder deutsche Bildungsnormen und -muster (mit)geprägt wurde - zur letztgenannten Gruppe gehörte übrigens auch Mailáth. Kurz und bündig: Für die deutschsprachige Literatur Ungarns war in den ersten Jahrzehnten des 19. Jahrhunderts charakteristisch, dass die Sprache zwar Deutsch war, ihr Inhalt aber Ungarisch blieb und stark durch patriotische Gefühle geprägt war. ${ }^{39}$ Und gerade diese Position der Autoren zwischen Sprachen und Kulturen relativierte die binäre Konstruktion des ,Eigenen' und ,Fremden'. 
Zunächst wird die konkrete Analyse von vier Märchen Mailáths unternommen, um 1) die in ihnen vermittelten Ungarnbilder auszuloten, 2) diese zu klassifizieren und 3) ihre Wurzeln zu bestimmen. Schließlich werden die Fragen diskutiert, ob Mailáth bei der Darstellung Ungarns deutschen Mustern folgte, inwiefern er ihr Fortbestehen förderte und ob er (selbstverständlich neben jenen deutschsprachigen ,Nationaldichtern' Ungarns, wie Karl Anton Gruber oder Christophorus Rösler) zur weiteren Tradierung bestimmter Ungarn-Topoi beitrug.

Die in den Märchen Mailáths (bzw. in ihren Rahmenhandlungen) aufkommenden Ungarnbilder lassen sich drei Gruppen zuordnen: 1) der Darstellung des fruchtbaren Ungarlandes, 2) der Erinnerung an die Zeit, als Ungarn als Bollwerk des christlichen Europa galt und 3) der Beschreibung der Bewohner des Landes. Diese Kategorien decken die gängigsten Ungarn-Topoi ab, die seit den Anfängen des deutsch-ungarischen Zusammenlebens das Denken über das Königreich und dessen Bewohner prägte. Es geht um a) den Topos ,fertilitas Pannoniae/Hungariae', b) um den Topos ,propugnaculum Christianitatis' sowie um c) Elemente des volkscharakterologischen Toposschatzes. ${ }^{40}$

Genauso wie seine Hungari-Zeitgenossen griff Mailáth gerne auf die Darstellung des fruchtbaren Bodens und der schönen Landschaften Ungarns zurück: ein Paradies auf Erden entfaltet sich in der Beschreibung jener Gegenden, in denen die Handlung der Märchen spielte. Ein Raster der Elemente des fertilitas-Topos wurde beispielsweise in der Erzählung Das Schwert Zuniga sichtbar. Die Handlung spielte sich in einer der „entzückendsten Gegenden in Ungarn,““11 im sogenannten ,Grantal' rund um den Bischofssitz Gran/Esztergom, zur Zeit der Türkenkriege ab. Die Landschaft um die Festung Revistye beschrieb Mailáth wie folgt:
„Die Berggruppen sind mannigfaltig, die Wälder grünen lustig drauf, in der Tiefe blühen die Wiesen üppig, reiche Kornfelder wogen, und der klare Fluss wälzt sich in mancherlei Krümmungen freudiglich; die alte Burg Revistye schaut ernst und nachdenklich die Stromlänge auf und nieder, der alten Zeiten mahnend. Kurz alles ist hier vereint, was durch seinen Anblick ein vaterländisches Herz zu erfreuen vermag. ${ }^{6}{ }^{6}$

Die Darstellung der dichten Wälder, der fruchtbaren Felder und des klaren Wassers entsprachen jenen Schemata, die in ihren Grundzügen seit der Antike, vorwiegend aber seit dem 15. Jahrhundert in Gebrauch waren. Interessant ist, dass dieser Topos früh in die ungarische Literatur Eingang fand: Bei Miklós Oláh nährte sich die detailreiche Schilderung des Reichtums des Königreichs wahrscheinlich daraus, sich über den schmerzhaften Verlust nach der Schlacht bei Mohács zu erheben. ${ }^{43}$ Spannenderweise griff Mailáth auf dieselben rhetorischen 
Bausteine des Topos zurück: Neben den Wiesen, Wäldern, Gewässern erhielt bei ihm auch die Präsenz von Edelmetallen im Boden Ober- und Niederungarns eine besondere Rolle.

Der in den literarischen Texten der Frühen Neuzeit mehrmals rezitierte exotische Reichtum des Landes, deren übertreibende Beschreibung dem Anspruch des nach Raritäten und Besonderheiten hungrigen Publikums entgegenkommen sollte, kehrte bei Mailáth als zentrales Motiv der Märchen zurück. Es hieß also nicht nur bei Happel: „Eysen war ich; Kupfer bin ich; Silber trag ich; Gold bedeckt mich;"44 bei Mailáth sind die Protagonisten keine geringeren Persönlichkeiten, als Eisen Laczi, drei Königstöchter mit goldenem, silbernem und eisernem Haar (Die Königstöchter) oder die Goldtochter des mit dem „Kupfergrafen von Nagi Bánia [Baia Mare/Frauenstadt/Nagybánya] ${ }^{645}$ wettenden Bergkönigs von Schemnitz/Banska Stiavnica/Selmecbánya (Die Salzgewerke). An dieser Stelle soll angemerkt werden, dass das Bild der goldreichen Bergwerke des Hauerlandes keine bloßen Imaginationen sind, sondern durch wirtschaftshistorische Fakten untermauert werden können. ${ }^{46}$ Jedenfalls entsprach dieses weit verbreitete Bild den Intentionen des Autors, auch Märchen, die nicht unbedingt im ,magyarischen“ Volksmund lebten, ${ }^{47}$ in einen ungarischen Kontext zu setzen.

Dass die Welt der Berge und Bergwerke auch voller Gefahren ist - denken wir nur an eine der bekanntesten Karpatenbeschreibungen von Daniel Speer ${ }^{48}-$ kam $^{2}$ auch in den Texten des Grafen zum Ausdruck. In einem der Märchen ist es gerade das Gold in den Gruben Oberungarns, das gierige und törichte Menschen in Gefahr bringt. In der Erzählung Der Schaz [sic!] findet einer der Protagonisten, Günther, ein Bürger aus der Zipser Stadt Käsmark/Kežmarok/Késmárk, ein Pergament, das über den Ort eines märchenhaften Schatzes Auskunft gibt: „Günter zog das Pergament hervor und sprach: vom Rhein bin ich heim gezogen, weil ich Kunde bekam vom Schaz [sic!], der in diesen Gebirgen verborgen. Seit Jahren späh“ ich nach diesem Blatt, dem einzigen, welches davon Kund gibt. Endlich ist es mein.“49 Dieses Zitat kann zugleich auch als ein Hinweis des Autors darauf gesehen werden, dass die stark übertriebenen Darstellungen der Schätze in den ungarischen Bergwerken weit über die ungarischen Grenzen hinaus, auch auf deutschem Sprachgebiet, bekannt waren. Das Pergament beschrieb in Anlehnung an einen Benediktinermönch die Geschichte des heidnischen Tolzán, der einst der Zauberkunst mächtig war - eine kleine Anspielung auf Ungarns Geschichte vor der Christianisierung - und der „die Quelle des Fruchtbarkeit des Landes, in dem es ihnen wol ging, zu zerstören" vorhatte..$^{50}$ Aufgrund dieser Legende will Günther mit seinen Gefährten diesen Ort, die Quelle der Fruchtbarkeit - „alles, was in Ungarn wächst und lebt, ist dort in Gold“51 - suchen. Was sie dann im Kohlbachtal in der Nähe von Leutschau/Levoča/Löcse finden, übertrifft ihre Vorstellungen: 
„Der ganze Berg war ein Goldgewölbe und goldne Strassen führten nach allen Seiten, Das trinkbar feuchte Gold rauschte in Strömen dahin, und goldne Fische aller Art spielten darin. [...] Auf goldenen Wiesen weideten leuchtende Rosse; in Füssern lag geprägtes Gold; frisch gekeltert schäumte goldener Wein, Schwerter und Pfleile, alles Kriegsgeräth war golden, goldene Bäume reckten ihre Kronen in die Höhe, und tausend Vögel zwitscherten die wunderbarsten Lieder." ${ }^{\text {(52 }}$

Das wundersame Naturphänomen fesselt die Reisenden dermaßen, dass sie die ihnen nur für eine einzige Stunde gewährte Zeit überschreiten und schließlich von Günthers Tochter gerettet werden müssen.

Ein anderes Beispiel, aufgrund dessen Parallelen zwischen den märchenhaften Barockdarstellungen und den Märchen Mailáths gezogen werden können, ist die „Legende der silbernen Birne' im Märchen Die Brüder. Lange Zeit hat sich in der Öffentlichkeit die These gehalten - mit diesem Thema haben sich übrigens auch die Wissenschaftsstars Theophrastus Paracelsus ${ }^{53}$ und Athanasius Grün beschäftigt - dass manche Pflanzen fähig sind, Metall aus der Erde zu ziehen und metallhaltige Früchte zu tragen. Eine Essenz der Schilderung der Fruchtbarkeit des ungarischen Bodens! Das Phänomen des sog. aurum vegetabile, das eng mit dem Tokajer Wein verknüpft war, hat nicht nur die Phantasie der Barockautoren (wie etwa Eberhard Werner Happel) bewegt, sondern lieferte u.a. für Gottfried Benjamin Hancke (Lob des ungarischen Weines) oder Johann Ludwig Georg Schwarz (Denkwürdigkeiten aus dem Leben eines Geschäftsmannes...) Material, ${ }^{54}$ aber auch für Karl Anton Gruber (Hymnus an Pannonia) und Christophorus Rösler (Tokayer Lied für seine Landsleute, Hymnus an Pannonia), was zugleich für die Kontinuität des fertilitas-Topos und des Goldmotivs einen Beweis liefert. Obwohl in den Märchen Mailáths der ungarische Wein nur rudimentär Erwähnung findet, begegnet der Leser bei ihm statt der Legende der goldenen Trauben und Weinreben mit jener der ,silbernen Birne‘. Die Früchte eines sonderbaren Baumes wuchsen im Garten des Königs, der sie wegen ihrer Kuriosität und wegen ihres guten Geschmacks gerne verzehrte. Als der Baum sieben Jahre lang keine Birnen trug, wurde der König sehr traurig. Laut der Legende saß eine Kröte unter dem Fuß des Baumes,

„die zieht alles Silber an sich, welches in den Baum aufsteigen sollte. Diese Kröte nun muss ausgegraben und erschossen werden, dann trägt der Baum wieder silberne Früchte. Man kann sie aber nur mit 24 diamantenen Kugeln erschießen, die zugleich auf sie gefeuert werden. “ 55 
Der Gold-, Silber-, Kupfer- und Salzgehalt des Bodens wird in mehreren Erzählungen angesprochen, etwa wenn die Protagonisten aus Goldbechern trinken oder bei Schlachten Goldhelme tragen. Edelmetalle scheinen von der ,magyarischen Märchenwelt' nicht zu trennen zu sein.

Obwohl in der deutschsprachigen sowie in der (lateinischsprachigen) ungarischen Literatur der fertilitas-Topos zusammen mit dem propugnaculum-Topos erschien, verlor Letzterer mit dem Ende des großen Türkenkriegs maßgeblich an realpolitischer Relevanz und somit an Wirkung. ${ }^{56}$ Nach einem gewissen Rückgang intensivierte sich die Ungarnrezeption auf deutschem Sprachgebiet während der Aufklärung, und das Bild Ungarns war fast noch ambivalenter als zuvor. Die Wahrnehmung des Landes und dessen Bevölkerung schwankte zwischen dem Bild des faulen, ungebildeten Ungarn und dem schneidigen Husaren. ${ }^{57}$ Das kann als ein, wenn auch blasses, Fortbestehen des propugnaculum-Topos gedeutet werden. Die Romantik entdeckte dann für sich den Bollwerk-Topos und revitalisierte das Bild vom mutigen Ungarn. Es entwickelte sich eine Literatur, die ungarische Geschichte im Rahmen üppiger Handlungsfülle darstellte, wobei die Autoren eine Vorliebe für die Ausgestaltung von Familiengeschichten und Einzelschicksalen zeigten, wie z.B. Joseph Gleich, Friedrich August Wentzel, Wilhelmine von Gersdorf oder Gottfried Tobias Schröer. ${ }^{58}$ Das Verteidiger-Bild kam dann auch bei namhaften ungarischen Dichtern auf, ${ }^{59}$ denken wir zum Beispiel an Kölcsey und an sein 1903 zur Nationalhymne deklariertes Gedicht Hymnus. ${ }^{60}$

\begin{abstract}
Dass der Bollwerk-Topos im 19. Jahrhundert eine Renaissance erlebte, ist in Mailáths Märchen auch ersichtlich. Mailáth, der nach seinen ersten literarischen Versuchen als Geschichtsschreiber tätig war und auch als solcher bekannt wurde, bearbeitete in seinem Märchenband auch Ereignisse der ungarischen Geschichte und setzte dort ihren prägenden Gestalten ein Denkmal. Neben Salomon, der siebte König Ungarns zwischen 1063 und 1074, thematisierte Mailáth die Geschichte des Herrn der Festung Revistye ${ }^{61}$ im Märchen Das Schwert Zuniga, der in einem Duell laut Kolos mit dem Bej von Lizenz/Losonc/Lučenec, ${ }^{62}$ laut anderen Quellen aber mit dem Bassa von Lewenc/Levive/Léva, ${ }^{63}$ ums Leben kam.
\end{abstract}

Beim Lesen der Märchen fällt auf, dass Mailáth nur manche Elemente des Bollwerk-Topos verwendete. Bei ihm entfiel die Darstellung der Festungen als christliche Bollwerke, hingegen konzentrierte er sich auf jene Personen, die als athleta Christi $^{64}$ tapfer gegen den Feind kämpften. Dies zeigt sich exemplarisch in der Erzählung Das Schwert Zuniga, in der er die Zeit der Türkenkriege in den Mittelpunkt stellt, ,als Ungarn von des Morgenlandes blutgierigen Wülfen bedrängt, dem edlen Ross seiner Haiden gleich, mit erstrebender Kraft, aber 
unbesiegtem Mute widerstand."“65 Sogar dieses einzige Zitat enthält eine Reihe von Elementen, die zu den rhetorischen Mitteln der Erzählungen über die Türkengefahr im Königreich Ungarn gehörten. Die Darstellung des Erbfeindes als Wölfe, Schlangen oder Bären gehörte genauso zur narrativen Tradition, wie die Beschreibung der Ungarn als ein Reitervolk, das heldenhaft und mutig in den oft aussichtslosen Krieg zog. Mailáth führte auch jene Tradition weiter, welche die fertilitas- und propugnaculum-Topoi, wie oben erläutert, miteinander verband. Als der alte Soldat und der deutsche Knabe aus Schemnitz am Tor der Festung Revistye ankommen, sagt der Alte zu seinem jungen Begleiter:

„Sieh dich indessen um bei uns ein, du scheinst erst kurz im heil'gen Ungarland zu sein, so präge dir's denn lebhaft ein, was sich dir darbietet. Was du jetzt und in der Burg siehst, wird dir wol eine freundliche Erinnerung bleiben für dein Leben." ${ }^{66}$

Der heilige und reiche Boden des Königreichs Ungarn hat die Krieger auch für den Kampf wider den Feind motiviert. Als der junge Schemnitzer Bergmann mit dem Alten über eine mögliche Schlacht diskutierte, ruf er bezaubert aus: ,'Ich bin viel herum gekommen in meinem Vaterland, aber nirgend hat es mir so wol gefallen, und gern möchte ich hier sterben, denn es mus [sic!] sich in dieser schönen Erde recht gut ruhen lassen." 67

Eng an den Bollwerk-Topos knüpft aber nicht nur der Fruchtbarkeit-Topos an, sondern auch die Darstellung der Ungarn als mutiges, sogar waghalsiges Soldatenvolk. Dies lässt sich auch im Schwert Zuniga nachvollziehen. In der Burg von Revistye spielt sich folgende Szene ab: Ein üppiges Nachtessen wird verzehrt, und dabei werden vaterländische Lieder gesungen und von ,frühere[n] türkische[n] Kämpfen und magyarische[n] Tapferkeit" ${ }^{\text {668 }}$ ist auch die Rede. Aber nicht nur Männer haben in der ungarischen Geschichte tapfer gegen den Feind gekämpft, auch die Frauen bilden hier keine Ausnahme. In der Erzählung von der Herrin von Ardó, die die Belagerung des Schlosses Groß-Scharosch/Vel'ký Šariš/ Nagysáros durch die Truppen des Königs Karl Robert I. thematisiert, erweist sich der alte Graf als ebenso mutig, wie seine Tocher, die ,des Krieges wol kundig und bereit [war], für ihres Vaters Sache ihr Leben zu lassen. “69 Der Erzähler stellt die Stimmung vor der Schlacht auf dem Schloss Sáros wie folgt dar:

„Im Schlosse Sáros war alles regsam. Der alte Graf war in der lezten [sic!] Nacht mit seinem ganzen Gefolg und zahlreichen Anhängern in das Schloss eingerückt. Vom Gipfel des Thurms, von den Zinnen der Mauern wehte heraus fordernd sein Banner; im Hof stand es riesig aufgepflanzt, ein Grab daneben, verkündend, das er, wenn er auch geschlagen, wenn auch die Mauer erstürmt, seine Sache bis auf den lezten [sic!] Mann verfechten würde.“70 
Die Darstellung der Kriegslage kann sogar mit den Beschreibungen der Eroberung der südungarischen Festung Sigeth, bei der die Soldaten einen Krieg auf sich nehmen mussten, den sie wegen deutlicher Überzahl des Gegners voraussehbar nicht gewinnen konnten, gewisse Ähnlichkeiten aufweisen.

Die Kampfbereitschaft des Schlossherrn und seiner Tochter, die „tapfer wie ein Mann" "71 war und die Führung der Schlacht von ihrem Vater übernahm, erstaunte die Soldaten im Heer des Königs Karl Robert. Der Graf erwidert beispielsweise den Antrag des königlichen Boten mit folgenden Worten:

\begin{abstract}
„Was ihr verheissen [sic!] beweget mich nicht, was ihr droht, schreckt mich nicht. Ihr verheisst mir ruhigen Besiz [sic!] meiner Güter, wenn ich zu Karl Robert übertrete? Ich werde sie gegen euch zu schüzen [sic!] wissen. [...] Ihr droht mir Tod und Untergang; der Schlachten Ausgang ist wechselnd, ihr könnt erliegen wie ich [...]; so lasset denn das Schwert walten, ob wir, ob ihr fallet, ist die Schlacht, ist der Tod ruhmreich. Niemand aber soll sagen, der Graf von Trentschin habe sich selbst dem Feind ungastlich erwiesen, darum nehmt an, was ich euch freundlich biete." ${ }^{\text {.72 }}$
\end{abstract}

Dieses Zitat beleuchtet übrigens weitere Elemente des Ungarn betreffenden volkscharakterologischen Toposschatzes und zeigt ihre enge Verflechtung miteinander auf. Der Schlossherr ist nicht nur bereit zum Kampf, sondern nimmt den Boten freundlich in Empfang. Die Gastfreundschaft, die ein zentrales Element der Ungarndarstellungen in der deutschen Literatur ausmachte, wurde diesmal mit der Legende der Herrin von Ardó verknüpft: ,jeder, der von [...] der Herrin von Ardó [...] was immer für eine Gabe bitten und sie erhalten würde, sie lieben müssen bis an sein Ende, ausschliesslich, unendlich, verzehrend, unglücklich."73

Die Herrin von Ardó war aber nicht nur für ihre Tapferkeit und Kriegskunst, sondern auch für ihre Schönheit berühmt. Damit hat Mailáth aber nicht ,etwas Neues' erfunden. Das Bild der schönen Frauen, ein ständig wiederkehrendes Motiv in den Märchen des Grafen (siehe z.B. Die Salzgewerke), blickt ebenso auf eine längere Geschichte zurück: Manche leiten dieses Bild sogar vom Mittelalter $a b .{ }^{74}$ Vielmehr ist hierbei die Kombination der Topoi der schönen und tapferen Frauen spannend. Damit hat Mailáth eine Tradition fortgesetzt, die seit dem 16. Jahrhundert literarisch belegt ist und als eine ,comparatio' und gradatio', als Vergleich und Steigerung, wahrgenommen werden kann. Selbst die Männer dienen mit ihrer Tapferkeit als Vorbild für andere Völker, aber durch den Kampf der Frauen wird oft die Ausweglosigkeit mancher Kämpfe zum Ausdruck gebracht. Denken wir nur an die ,Frauen von Erlau/Eger', die zu einem ungarischen Wiederstandmythos avancierten. ${ }^{75}$ 
Zum volkscharakterologischen Toposschatz gehört auch - das hängt zum Teil mit der Darstellung der Ungarn als ein kriegerisches Volk zusammen - die Beschreibung der östlichen Herkunft der Magyaren. Mailáth griff auch bewusst auf das Bild des ,orientalischen Steppenvolkes' zurück. Er legitimiert sogar mithilfe dieses Images, warum er gerade ,magyarische Märchen und Sagen' sammelte: In der Erzählung über die Herrin von Ardó wird - um die Legende der wunderschönen Frau einzubetten - erklärt, dass die ungarischen Soldaten

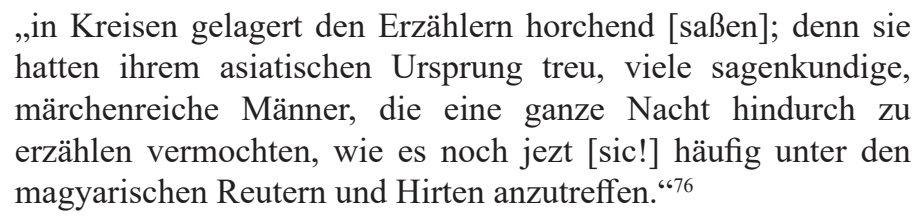

Mailáth betont an mehreren Stellen die orientalischen Züge seiner Märchen, die er mit der Herkunft des Volks erklären wollte. ${ }^{77}$ In den Anmerkungen schreibt er sogar - und diese Meinung wurde von Mailáths Rezensenten auch rezitiert ${ }^{78}$ - dass die „magyarischen Erzähler [...] eine der vielfachen Spuren der orientalischen Abkunft des Volkes“ seien und dass der „Charakter der magyarischen Märchen [...] auch ein ganz anderer, als jener der Abendländischen Völker" sei. ${ }^{79}$ An dieser Stelle sei angemerkt, dass die Thematisierung einer vermeintlich asiatischen Abstammung der ungarischen Nation seit dem Mittelalter in der deutschen Literatur belegt werden kann (siehe z.B. das Gespräch von Hildebrand und Hadubrand im Hildebrandslied) ${ }^{80}$ dass aber diese Eigenschaft meistens in einem negativen Kontext angesprochen wird. Diese Meinung änderte sich am Ende des 18., Anfang des 19. Jahrhunderts: Die Romantiker entdeckten die exotischen Aspekte des Ungarlandes, und das wilde Reitervolk des Osten verwandelte sich in ihrer Betrachtungsweise zu freiheitsliebenden, selbstbestimmten Menschen auf der Heide. Dieses romantische Ungarnbild, das als Trias von ,Liebe, Wein und Freiheit ${ }^{`}$ zusammengefasst werden kann, ${ }^{81}$ verbreitete sich nicht nur dank der Tätigkeit Nikolaus Lenaus und Karl Isidor Becks, sondern auch durch die Anthologien deutsch-ungarischer Autoren, wie Gaal, Mailáth oder Toldy (geb. Schedel). ${ }^{82}$

\section{Ausblick und Fazit - Zur Rezeption der Magyarischen Sagen}

Zusammenfassend lässt sich feststellen, dass Mailáths Märchen vorwiegend positive imagotype Elemente, die auf eine lange Geschichte in der deutschsprachigen Literatur zurückblickten, überlieferte. Er operierte bewusst mit Images, die bei seiner entweder von der deutschen Romantik oder durch die Hormayr'sche Idee der Gesamtmonarchie (mit)geprägten Leserschaft gut ankommen mussten. Diese 
Haltung lässt sich mit seiner Intention erklären, ungarisches Kulturgut zu vermitteln, wodurch er zum Aufbau einer positiven ,nation brand“ beitragen wollte.

Damit hat er sich, bewusst oder unbewusst, einem gewissen literarischen Diskurs und einer starken Schematisierungstendenz angeschlossen. Das Ungarnbild war nämlich auf deutschem Sprachgebiet im 18. Jahrhundert mehr oder weniger vorprogrammiert und der "Trend der Generalisierung war stärker als je zuvor." ${ }^{\text {"83 }}$ Der Grad der Schematisierung wurde durch den Zuwachs von Beschreibungen, die auf eigenen (Reise)Erfahrungen basierten (wie. z.B. im Falle von Ernst Moritz Arndt), auch nicht geringer, denn die Autoren griffen in der Hoffnung auf einen Erfolg beim Publikum auf gewisse narrative Traditionen zurück. Wie Tarnói die Lage um die Jahrhundertwende sehr zutreffend zusammenfasste: „Die Dialektik des Individuellen und des Allgemeinen, des Momentanen und historisch Tradierten scheint auf dem Gebiet der Länderbilder innovative Wirkungen nicht so recht zu fördern wollen." ${ }^{\text {84 }}$ Die oben angesprochene Trias ,Liebe, Wein Freiheit", die den Schwerpunkt romantischer Ungarnbilder ausmachte, resultierte ebenfalls aus diesem Phänomen. Im Vergleich zum 18. Jahrhundert waren diese Images jedoch viel positiver, und das Gesamtbild über Ungarn fiel insgesamt günstiger aus.

Laut Veit haben gerade jene Anthologien zur Entstehung dieses Musters beigetragen, die die ungarische Literatur und überhaupt das deutschsprachige Ausland mit dem ungarischen Kulturgut vertraut machen wollten. ${ }^{85}$ Nach Ansicht der Verfasserin haben Mailáth sowie seine Hungari-Kollegen nicht nur zur Weitertradierung schematisch strukturierter Ungarnbilder beigetragen. Sie haben ihren Verdienst auch darin, dass bestimmte Elemente des fremdbestimmten Ungarn-Images auch in die Selbstdarstellung der ungarischen Nation Eingang fanden. Obwohl die ungarische Literatur (vor allem aber die auf Latein verfassten Texte) des 18. Jahrhunderts manche oben genannte Topoi verwendete, verbreiteten sich in ihr diese Bilder aber besonders im 19. Jahrhundert, zur Zeit eines nationalen Erwachens. Die Texte deutschschreibender Hungari, die einen expliziten Ungarnbezug in ihrer Thematik aufwiesen, lassen sich als Meilensteine auf jenem Weg charakterisieren, der von der Fremddarstellung zur Verinnerlichung von - selbstverständlich vorwiegend positiven - Fremdbildern und zu deren Umwandlung in Eigenbilder führte. Ein geeignetes Beispiel dafür ist der bereits erwähnte Hymnus von Ferenc Kölcsey aus dem Jahr 1823. In diesem Werk kehrten alle der oben erwähnten Bausteine des deutschsprachigen Ungarnbildes zurück, die bereits um 1800 auch bei deutsch-ungarischen Autoren wie Gruber oder Rösler aufgetaucht waren: dank Gottes Gnade wiegt sich auf den ungarischen Feldern reifes Getreide, auf den Tokajer Weinbergen fließt Nektar (Elemente des Fertilitas-Topos), trotzdem muss das Volk in diesem Land viel leiden und gegen einen von außen kommenden Feind (gegen Mongolen und Osmanen) kämpfen (Elemente des propugnaculum-Topos).

Seine Märchen übten neben dieser indirekten auch eine direkte Wirkung auf Mailáths Leserschaft aus. Die erste, 1825 veröffentlichte Ausgabe der Magyari- 
schen Sagen und Mährchen war im deutschen Sprachraum ein Erfolg, und dies hat den Autor wahrscheinlich auch dazu ermutigt, eine zweite, erweiterte Auflage in zwei Bänden 1837, erneut beim renommierten Cotta-Verlag, herauszubringen. Die deutschen und österreichischen Rezensenten der Zeitschriften Wiener Theater-Zeitung, Wiener Zeitschrift oder des Stuttgarter Morgenblattes lobten die Art der literarischen Darbietung der Märchen, die der Autor mit viel Phantasie bearbeitet habe und die sich für viele als eine leichte und unterhaltsame Lektüre erweisen konnte. ${ }^{86}$

In Ungarn ernteten die Märchen Mailáths auch Erfolg, insbesondere bei Ferenc Kazinczy, der die Märchen nach ihrem Erscheinen zu übersetzen begann. ${ }^{87}$ Die einzelnen Stücke des Bandes erschienen dank Kazinczy, Pál Szemere und Gábor Döbrentei in verschiedenen ungarischen Almanachen, wie etwa im Taschenbuch Hébe, Aurora und Muzárion. ${ }^{88}$ Obwohl Kazinczy mit der Übersetzung bereits 1828 fertiggestellt war und er Toldy den Auftrag gab, einen Verlag für das Manuskript zu finden, sollte seine ungarische Fassung erst 36 Jahre später, im Jahr 1864, erscheinen. Der Herausgeber war Gábor Kazinczy. ${ }^{89}$

Die deutsche Version wurde auch in Ungarn rezensiert. In der Buchbesprechung der Tudományos Gyüjtemény (Wissenschaftliche Sammlung) wurde insbesondere die Form der bis dahin immer nur einzeln veröffentlichten Märchen gelobt, mit denen der Autor insbesondere im Kreis der jungen Leserschaft Lust am Lesen wecken konnte. ${ }^{90}$ Der Rezensent der Zeitung Magyar Kurir (Ungarischer Kurier) war generell von den Unternehmen Mailáths begeistert, insbesondere was die Magyarische Gedichte und die Magyarische Sagen und Mährchen anbelangte. Von Letzterem schrieb er, dass man vorsah, die ungarische Übertragung noch im Jahr des Verfassens der Rezension zu veröffentlichen. ${ }^{91}$ Obwohl an anderen Stellen auch die Veröffentlichung der ungarischen Fassung angekündigt wurde, ${ }^{92}$ wissen wir heute, dass sie in der Tat noch einige Jahrzehnte lang auf sich warten ließ. Die von Gábor Kazinczy betreute ungarische Ausgabe wurde dann auch mehrfach rezensiert. ${ }^{33}$ In der Buchbesprechung der Zeitschrift Koszorú (Kranz) betonte z.B. der Rezensent aus einer gewissen historischen Perspektive heraus die langhaltige Wirkung der Mailáth'schen Märchen, die sogar die Grimms geprägt haben soll:

„Die Brüder Grimm begannen aus den Märchen Mailáths und Gaals unsere Volksmärchen kennen zu lernen. Diese kompetenten Kritiker des Volksmärchen tadeln zwar beide wegen der ungenauen Auffassung [der Gattung Volksmärchen] und wegen der komplizierten Erzählweise [...], aber sie finden darin genügend Material zum Vergleich und zur Charakterisierung des ungarischen Volksmärchens [...]." ${ }^{\text {"94 }}$ 
Die Nachricht von den Magyarischen Sagen und Mährchen Mailáths kam aber nicht nur bei den Grimms an. Zusammen mit den Ausgaben Gaals und Pulszkys kurbelte die Ausgabe den Prozess des Sammelns volkstümlicher Stoffe an. Obwohl Toldy noch in den 1820ern die Gattung des Volksmärchens offensichtlich nicht als so bedeutend eingeschätzt hatte, ${ }^{95}$ wie in seiner späteren Schaffensperiode, ${ }^{96}$ kam es um die Mitte des 19. Jahrhunderts auch in Ungarn zu einer Hochkonjunktur der Gattung. 1843 kündigte die 1836 in Pest gegründete Kisfaludy Gesellschaft, die sich der Entwicklung des literarischen Geschmacks sowie der Pflege der ungarischen Belletristik widmete, das Sammeln, die Aufbewahrung und Pflege des ungarischen Märchen-, Sagen- und Volksliedschatzes an ${ }^{97}$ Dieser Aufforderung schlossen sich Märchensammler wie Arnold Ipolyi (Magyar mythologia, Pest 1854), János Kriza (Vadrózsák [Wildrosen], Klausenburg 1863), oder János Erdélyi (A nép költészete [Die Dichtung des Volkes], Pest 1869) an, ${ }^{98}$ die auch oft auf Mailáths Anthologie Bezug nahmen.99

Zusammenfassend kann also festgestellt werden, dass Mailáths Märchensammlung aus mehreren Perspektiven der Zeit voraus war. Die Gründe dafür können wie folgt summiert werden:

1. Mailáth als Deutsch-schreibender Hungarus hatte aufgrund seiner deutschen Erziehung und österreichischen Prägung einen anderen Bezug zu Ungarn als seine ungarischen Schriftstellerkollegen. Er glaubte, er könnte dem Interesse des Landes am effizientesten durch die Übersetzung literarischer Texte (seien es Gedichte oder Märchen) ins Deutsche und durch die Vermittlung des ungarischen Kulturgutes ins Ausland dienen. Diese Texte waren aber auch gut dafür geeignet, durch die Betonung des Exotischen das Bild über das Land in eine positive Richtung zu lenken.

2. Mailáths Blick auf die Gattung Märchen war ein anderer als jener seiner ungarischen Zeitgenossen. Er erkannte viel früher, dass Märchen die wesentlichen Charakterzüge eines Volkes widerspiegeln, ${ }^{100}$ und er wollte sie in Anlehnung an die Grimms und an Gaal auch den Ungarn vertraut machen. Es lag allerdings nicht an ihm, dass das Volksmärchen erst später in der ungarischen Literatur an Bedeutung gewinnen sollte.

Aus diesen Überlegungen geht hervor, dass Mailáth eine bedeutende Vermittlerfigur zwischen dem deutschen und deutschsprachigen Kulturraum war. Aufgrund seiner vielschichtigen Tätigkeit als Schriftsteller, Übersetzer, Märchensammler und Geschichtsschreiber ist es ihm gelungen, eine Brücke zwischen zwei Kulturkreisen zu schlagen. Er vermittelte aber nicht nur Informationen über das Land, in dem er geboren wurde, über dessen Leute, Literatur, Geschichte, Sprache und Kultur, sondern er transferierte auch literarische Gattungen und Images, die auch von einem breiteren Leserkreis wahrgenommen wurden. 


\section{Anmerkungen}

1 Zu seiner Biographie siehe u.a. Endre Barát: Magyar foúr - német költő és történetíró. Százötven éve született gróf Mailáth János [Ungarischer Magnat - Deutscher Dichter und Geschichtsschreiber. Graf Johann Mailáth wurde vor 150 Jahren geboren]. In: Literatura 11 (1936), S. 273-275, sowie István Kolos: Gróf Mailáth János 1786-1855 [Graf Johann Mailáth 1786-1855]. Budapest: Kir. Magyar Egyetemi Nyomda 1938.

2 Vilmos Voigt: A magyar mese- és mondakutatás bécsi triásza [Wiener Trias der ungarischen Märchen- und Sagenforschung]. In: József Jankovics [et.al.] (Hrsg.): A magyar nyelv és kultúra a Duna völgyében [Die ungarische Sprache und Kultur im Donauraum]. Bd. 1. Budapest/ Wien: Nemzetközi Magyar Filológiai Társaság 1989, S. 375-379.

3 Vgl. dazu Bleyer, Jakab: Hazánk és a német philológia a XIX. század elején [Ungarn und die deutsche Philologie am Anfang des 19. Jahrhunderts]. Budapest: MTA 1910 (=Értekezések a nyelv és széptudományok köréből 21/9), S. 50.

4 Dass Mailáth nur einen einzigen (nicht kommentierten) Band der Kalocsaer Handschriften veröffentlichte, untermauert die in der Forschungsliteratur verbreitete These, dass er mit der Bearbeitung der Handschriften überfordert war. Die Ausgabe ist, wie Rezensenten und die spätere Forschung darauf hinwiesen, nicht fehlerfrei gelungen. Siehe dazu u.a. Leipziger Literaturzeitung Nr. 172 (8. Juli 1818), S. 1369-1375, sowie Hartmann von Aue: Der arme Heinrich. Überlieferung und Herstellung. Hg. von Erich Gierach, Heidelberg: Winter 1925, S. X.

5 Varga S., Pál: Kunstzentrierte Entfaltung des Literarischen. Die klassische ungarische Literatur 1825-1890. In: Ernő Kulcsár Szabó (Hrsg.): Die Geschichte der ungarischen Literatur. Eine historisch-poetologische Darstellung. Berlin/Boston: de Gruyter, S. 133-263, hier S. 146.

6 Siehe dazu ausführlich Orsolya Lénárt: Johann Graf Mailáth und Ferenc Kazinczy. Die Geschichte einer langjährigen (Brief-)Freundschaft. In: Jahrbuch der ungarischen Germanistik (2018), S. 141-164.

7 Diese Sammlung wurde auch 1837, in einer ergänzten Form mit insgesamt 24 Märchen und Sagen, beim Stuttgarter Cotta Verlag veröffentlicht. Im vorliegenden Aufsatz befasst sich die Verfasserin jedoch ausschließlich mit der ersten Auflage aus 1825.

8 Vgl. dazu Wiener Theater-Zeitung. Jg. 18, Nr. 55 (7. Mai 1825), S. 231-232.

9 Vgl. dazu G[ábor] Verbegyi: Külföldi Literatura. Magyarok által, vagy Idegenektől, Hazánkat illető Külföldi nyelven íratott könyvek esmertetése [Besprechung der Ungarn betreffenden, von Ungarn oder Ausländern herausgegebenen, fremdsprachigen Schriften]. In: Tudományos Gyüjtemény [Wissenschaftliche Sammlung]. Jg. 9, Nr. 4 (1825), S. 108-114, hier S 112.

10 Johann Graf Mailáth: Die Salzgewerke. In: Archiv für Geschichte, Statistik, Literatur und Kunst. Nr. 1-2 (1824), S. 1-6.

11 Johann Graf Mailáth: Tündér Ilona [Die Fee Helene]. In: Muzárion. Élet és literatúra [Muzárion. Leben und Literatur]. Bd. 3, Teil 17 (1829), S. 171-183.

12 Inge Stephan: Kunstepoche. In: Wolfgang Beutin: Deutsche Literaturgeschichte. Von den Anfängen bis zur Gegenwart. Stuttgart - Weimar: Metzler 20168, S. 185-240, hier S. 211.

13 Zur ungarischen Literaturgeschichte in den ersten Jahrzehnten des 19. Jahrhunderts siehe u.a. Varga, Kunstzentrierte Entfaltung, S. 133-263.

14 Bleyer, Hazánk és a német philológia, S. 5-7, sowie S. 49.

15 Zur Geschichte der Ausschreibung siehe Leander Petzoldt: Einführung in die Sagenforschung. Konstanz: UVK 1999, S. 29-38.

16 An dieser Stelle soll angemerkt werden, dass es bereits um 1800 Autoren gab, die ihre Aufmerksamkeit auf die Folklore richteten. Man muss zugleich bedenken, dass das Märchen am Anfang des 19. Jahrhunderts von der ungarischen Intelligenz eher geringgeschätzt wurde. Vgl. dazu Zoltán Ujváry: A folkórkutatás eredményei a XIX. században [Ergebnisse der Folklore- 
forschung im 19. Jahrhundert]. Debrecen: Bölcsész Konzorcium 2006 (= Nemzeti, vallási és hagyományos gazdálkodási terek szellemi öröksége IV), S. 26.

17 Voigt, A magyar mese- és mondakutatás bécsi triásza, S. 375.

18 Ujváry, A folkórkutatás eredményei a XIX. században, S. 5.

19 Joseph von Hormayr: Vorwort zur Rubrik Sagen und Legenden, Zeichen und Wunder. In: Taschenbuch für vaterländische Geschichte. Bd. 22 (1841), S. 264-276, hier S. 265.

20 Vilmos Voigt: A magyarországi folklorisztikai textológia eredményei és feladatai [Ergebnisse und Aufgaben der ethnographischen Textologie in Ungarn]. In: Hungarológiai Közlemények [Beiträge zur Hungarologie]. Jg. 12, Nr. 42-43 (1980), S. 29-48, hier S. 31.

21 Gyula Kunzer: Hormayr és az egykorú magyar irodalom [Hormayr und die zeitgenössische ungarische Literatur]. Pécs: Dunántúl Egyetemi Nyomdája 1930, S. 18.

22 Ferenc Toldy: Irodalmi arcképei és újabb beszédei [Literarische Porträts und neuere Reden]. Pest: Emich 1856, S. 77.

23 „In Georg Gaal wurde, geprägt durch seine jugendlichen Erinnerungen an die Bewegung Grimms in Deutschland, der Wille wach, den in den unteren Gesellschaftsschichten der Nation noch lebendigen Märchenschatz zusammenzusammeln.“[„Gaal György, ifjukori visszaemlékezései s a Grimm által Németországban támasztott mozgalom be folyása alatt azon szándékot érlelte, a nemzet alsóbb rétegein még ifju fris életet élő mesfikincset összeszedni.“] In: Ebda, S. 82.

24 Edina Zvara: Gaál György (1783-1855), a mesegyüjtő tudós könyvtáros. Egy javított életrajz [Georg Gaal (1783-1855), Märchensammler und gelehrter Bibliothekar. Eine korrigierte Biographie]. In: Ethnographia. Jg. 126, Nr. 3 (2015), S. 79-92, hier S. 79.

25 Voigt, A magyar mese- és mondakutatás bécsi triásza, S. 375.

26 Johann Graf Mailáth: Willi Tanz. In: Wiener Zeitschrift. Jg. 6, Nr. 155 (27. Dezember 1821), S. 1301-1305.

27 Vgl. János Gróf Mailáth: Villi táncz. In: Aurora (1822), S. 193-207.

28 Johann Graf Mailath: Ofens Rückeroberung im Jahr 1686, In: Taschenbuch für die vaterländische Geschichte 1824, S. 312-333.

29 Freyherr von M...y [d.i. Alajos Mednyánszky]: Péter von Szápár. In: Hesperus 43 (1816), S. $337-341$.

30 Ujváry, A folkórkutatás eredményei a XIX. században, S. 42.

31 [Mednyánszky, Alois]: Die Mauerblende zu Budetin. In: Taschenbuch für vaterländische Geschichte (1824), S. 176-189.

32 Várady, Zoltán: Gróf Mailáth János szerepe a magyar irodalomban [Die Rolle des Grafen Johann Mailáth in der ungarischen Literatur]. Máramarossziget: Berger 1911, S. 17.

33 Ujváry, A folkórkutatás eredményei a XIX. században, S. 44.

34 Siehe dazu u.a. Hugo Dyserinck: Komparatistik. Eine Einführung. Bonn: Bouvier 1981 (= Aachener Beiträge zur Komparatistik 1), Manfred S. Fischer: Nationale Images als Gegenstand vergleichender Literaturgeschichte. Untersuchungen zur Entstehung der komparatistischen Imagologie. Bonn: Bouvier 1981, sowie Manfred Beller, Joseph Theodoor Leerssen (Hrsg.): Imagology: The Cultural Construction and Literary Representation of National Characters: a Critical Survey. Amsterdam/New York: Rodopi 2007.

35 Siehe dazu u.a. Alois Wierlacher, Corinna Albrecht: Kulturwissenschaftliche Xenologie. In: Ansgar Nünning, Vera Nünning (Hrsg.): Konzepte der Kulturwissenschaften. Theoretische Grundlagen-Ansätze-Perspektiven. Stuttgart - Weimar: Metzler 2003, S. 280-306.

36 Tünde Radek: Das Ungarnbild in der deutschsprachigen Historiographie des Mittelalters. Frankfurt a. M.: Peter Lang 2008 (= Budapester Beiträge zur Literaturwissenschaft 12), S. 29.

37 Siehe dazu u.a. Kosellecks Theorie über die asymmetrischen Gegenbegriffe in: Koselleck, Reinhart: Vergangene Zukunft. Zur Semantik geschichtlicher Zeiten. Frankfurt a. M.: Suhrkamp 1979, S. 213. 
38 Siehe dazu u.a. László Sziklay: A magyarországi nem magyar nyelvủ sajtó kezdetei [Anfänge der nicht-ungarischen Presse in Ungarn]. In: Magyar Könyvszemle [Ungarischer Bücherschau]. Jg. 97, Nr. 1-2 (1981), S. 23-34, hier S. 23.

39 László Tarnói: Ungarnimage um 1800 (Ungarn: Heimat und/oder Fremde - auf deutsch). In: Peter Plener, Péter Zalán (Hrsg.): ,[...] als hätte die Erde ein wenig die Lippen geöffnet [...].“ Topoi der Heimat und Identität. Budapest: ELTE 1997 (= Budapester Beiträge zur Germanistik 31), S. 87-101, hier S. 88-91.

40 Zur Präsenz dieser Topoi in der deutschen Literatur siehe u.a. Imre Mihály: „Magyarország panasza.“ A Querela Hungariae toposz a XVI-XVII. század irodalmában [Klage Ungarns. Der Topos Querela Hungariae in der Literatur des 16.-17. Jahrhunderts]. Debrecen: Kossuth 1995, Orsolya Lénárt: Der Ungarische Kriegs-Roman. Medien, Wissen und Fremdwahrnehmung bei Eberhard Werner Happel. Wien: nap 2016 (= Mitteleuropäische Geschichte und Kultur - Studienreihe 1), Katalin Németh S.: Magyarország a 17. századi német nyelvü leírások tükrében [Ungarn im Spiegel deutschsprachiger Reisebeschreibungen des 17. Jahrhunderts]. In: Ferenc Kerényi, Gábor Kecskeméti (Hrsg.): Visszapillantó-tükör [Rück-Spiegel]. Budapest: Universitas 2000, S. 15-24, Andor Tarnai: Extra Hungariam non est vita... (Egy szállóige történetéhez) [Extra Hungariam non est vita... (Zur Geschichte eines Sprichwortes)]. Budapest: Akadémiai 1969, sowie J. János Varga: Europa und „Die Vormauer des Christentums.“ Die Entwicklungsgeschichte eines geflügelten Wortes. In: Bodo Guthmüller, K Wilhelm ühlmann (Hrsg.): Europa und die Türken in der Renaissance. Tübingen: Niemeyer 2000 (= Frühe Neuzeit 54), S. $55-63$.

41 Johann Graf Mailáth: Magyarische Sagen und Mährchen. Brünn: Trassler 1825, S. 87.

42 Ebda., S. 88.

43 Mihály Imre: A Querela Hungarie toposz retorikus gyökerei [Rhetorische Wurzeln des Topos Querela Hungariae]. In: István Bitskey (Hrsg.): Toposzok és exemplumok régi irodalmunkban [Topoi und Exempel in der älteren ungarischen Literatur]. Debrecen: Kossuth 1994 (= Studia Literaria 48), S. 7-21, hier S. 16-17.

44 Eberhard Werner Happel: Der Ungarische Kriegs-Roman. Bd. 1. Ulm: Wagner 1685, S. 413.

45 Mailáth, Magyarische Sagen, S. 74.

46 Géza Pálffy: A Magyar Királyság és a Habsburg Monarchia a 16. században [Das Königreich Ungarn und die Habsburg-Monarchie im 16. Jahrhundert]. Budapest: História 2010, S. 224.

47 Vgl. dazu József Hála, Ildikó Landgraf: Magyarországi bányászmondák [Ungarische Bergmannsmärchen]. Rudabánya: Érc- és Ásványbányászati Múzeum Alapítvány 2010, S. 29.

48 Daniel Speer: Ungarischer oder Dacianischer Simplicissimus. Ulm: [Wagner] 1683, S. 233.

49 Mailáth, Magyarische Sagen, S. 115.

50 Ebda, S. 118.

51 Ebda., S. 119.

52 Ebda., S. 126.

53 Vgl. mit Philippus Theophrastus Paracelsus: Der Hermetische Nord-Stern. Frankfurt/Leipzig: Kraus 1771, S. 63.

54 Siehe dazu Orsolya Lénárt: Der Tokajer Wein und das Aurum vegetabile. Das Bild des fruchtbaren Ungarns in den Werken Eberhard Werner Happels. In: Jahrbuch der ungarischen Germanistik (2014), S. 83-98.

55 Mailáth, Magyarische Sagen, S. 160.

56 Vgl. dazu Paul Srodecki: Antemurale Christianitatis. In: Joachim Bahlcke, Stefan Rohdewald, Thomas Wünsch (Hrsg.): Religiöse Erinnerungsorte in Ostmitteleuropa. Konstitution und Konkurrenz im nationen- und epochenübergreifenden Zugriff. Berlin: De Gruyter 2013, S. 804-822, hier S. 813. 
57 Siehe dazu Gabriella Schubert: Ungarnbilder. Hintergründe. Mythen. In: Zeitschrift für Balkanologie. Bd. 47, Nr. 2 (2011), S. 202-217, hier S. 208-209.

58 Horst Fassel: Ungarnbilder in der deutschen Literatur. Nachwort. In: Ders. (Hrsg.): Pannonien Vermessen. Ungarnbilder in der deutschen Literatur. Stuttgart: Ebner 2004 (= Miteinander. Schriftenreihe des Ungarischen Kulturinstituts Stuttgart 2), S. 333-378, hier S. 347-348.

59 Srodecki, Antemurale Christianitatis, S. 813.

60 Das Gedicht erschien zuerst 1829 im Almanach Aurora. Vgl. dazu Aurora (1829), S. 267-270.

61 Aller Wahrscheinlichkeit nach geht es um Zsigmond Dóczy. Vgl. dazu Iván Nagy: Magyarország családai [Die Familien Ungarns]. Bd. 3. Pest: Beimel 1858, S. 337.

62 Kolos, Gróf Mailáth János, S. 66.

63 Samu Borovszky (Hrsg.): Magyarország vármegyéi és városai. Bars vármegye [Ungarns Komitate und Städte]. Budapest: Apolló 1903, S. 48.

64 Lajos Terbe: Egy európai szállóige életrajza. Magyarország a kereszténység védöbástyája [Biographie eines europäischen Sprichwortes: Ungarn als Bollwerk des Christentums]. Budapest: Egyetemi nyomda 1937, S. 50.

65 Mailáth, Magyarische Sagen, S. 88.

66 Ebda., S. 89.

67 Ebda., S. 90.

68 Ebda., S. 95.

69 Ebda., S. 18-19.

70 Ebda., S. 18.

71 Ebda., S. 18-19.

72 Ebda, S. 29-30.

73 Ebda., S. 26.

74 Siehe dazu F. András Balogh: Nachwirkungen von Motiven und Topoi der älteren deutschen Literatur im Ungarischen Simplicissimus des Georg Daniel Speer. In: Dieter Breuer, Gábor Tüskés (Hrsg.): Das Ungarnbild in der frühen Neuzeit. Der Ungarische oder Dacianische Simplicissimus im Kontext barocker Reiseerzählungen und Simpliziaden. Bern [et.al]: Peter Lang 2005 (= Beihefte zu Simpliciana 1), S. 95-110, hier S. 97-98.

75 Wolfgang Libal: Ungarn. München: Prestel 1987, S. 269.

76 Mailáth, Magyarische Sagen, S. 14.

77 Vgl. dszu Kolos, Gróf Mailáth János, S. 64.

78 Siehe dazu die Rezension im Morgenblatt für gebildete Stände. Beiblatt Literaturblatt. Nr. 24 (24. März 1826), S. 93-96, insbes. S. 93.

79 Mailáth, Magyarische Sagen, S. 279.

80 Siehe dazu András Vizkelety: „Du bist ein alter Hunne unmäßig schlau... “ In: Klára Berzeviczy [et. al.] (Hrsg.): Ad. fontes. Válogatott tanulmányok - Ausgewählte Schriften. Budapest: Szent István Társulat 2011, S. 351-359.

81 Christine Schlosser: Zwischen ,Pußta-Romantik' und Moderne. Zur Rezeption ungarischer Versdichtung in deutschsprachigen multilateralen Anthologien (1848-1915). In: Helga Essmann, Udo Schönig (Hrsg.): Weltliteratur in den deutschen Versanthologien des 19. Jahrhunderts. Berlin: Schmidt 1996, S. 311-334, hier S. 315.

82 Zita Veit: Schemabasierte Repräsentation: Pusztaromantik im Dienste der deutschen Romantik. In: Klára Berzeviczy, László Jónácsik, Péter Lőkös (Hrsg.): Mitteleuropäischer Kulturraum. Völker und religiöse Gruppen des Königreichs Ungarn in der deutschsprachigen Literatur und Presse (16-19. Jahrhundert). Berlin: Frank\&Timme 2015, S. 167-182, hier S. 167.

83 László Tarnói: Deutschsprachige Ungarnbilder um 1800. In: Holger Fischer (Hrsg.): Ungarnbild in Deutschland, Deutschlandbild in Ungarn. Materialien des wissenschaftlichen Sympo- 
siums am 26. und 27. Mai 1995 in Hamburg. München: Südosteuropa-Gesellschaft 1996, S. 31-46, hier S. 32.

84 Tarnói, Deutschsprachige Ungarnbilder um 1800, S. 32.

85 Veit, Schematisierte Repräsentation, S. 167.

86 Siehe dazu die Rezensionen in: Wiener Theaterzeitung. Jg. 18, Nr. 55 (7. Mai 1825), S. $231-$ 232, Wiener Zeitschrift. Nr. 33 (17. März 1825), S. 279, Morgenblatt für gebildete Stände. Beiblatt Literatur-Blatt. Nr. 24 (24. März), S. 93-96, Morgenblatt für gebildete Stände. Literatur-Blatt. Jg. 32, Nr. 121 (30. November 1838), S. 481, sowie Repertorium der gesamten deutschen Literatur. Bd. 16. Leipzig: Brockhaus 1838, S. 179.

87 Vgl. dazu den Brief Kazinczys an Mailáth vom 13. April 1825 (Brief 4475) in János Váczy (Hrsg.): Kazinczy Ferenc összes müvei. Harmadik osztály. Levelezés [Sämtliche Werke von Ferenc Kazinczy. Dritte Abteilung. Briefwechsel]. Bd. 19. Budapest: MTA 1909, S. 320.

88 Siehe dazu Hébe (1824), S. 149-170, Aurora (1822), S. 195-207, Aurora (1824), S. 49-68, sowie Muzárion. Bd. 3, Teil 17 (1829), S. 171-183, S. 183-199, S. 199-219, sowie Muzárion. Bd. 4, Teil 27 (1829), S. 289-306.

89 Kolos, Gróf Mailáth János, S. 69-70.

90 „Itt előadatnak a’ Szerző Urnák eddig egyenként közlött Novellái több más Magyar Országi tündéi* mesékkel együtt szép romántos formában, melly az egészet méltán megkedvelteti az olvasást kedvelőkkel.“ In: Verbegyi, Külföldi Literatura, S. 112.

91 „Der liebwürdige Graf schreibt auf Deutsch, aber auch auf Ungarisch, wie wir es aus ungarischen Taschenbüchern wissen. Zuerst bearbeitete er Gedichte für jene, die so gesagt kein Ungarisch verstehen. So wurde er auf den Weg der Poesie geführt, auf dem er geblieben ist. Er hätte auch seine eigenen Gedichte in die Sprache seiner Nation übersetzt, aber seine Bescheidenheit hat es ihm nicht erlaubt. Stattdessen widmete er seine Zeit der ungarischen und der deutschen Literatur und übersetzte unsere Gedichte ins Deutsche; [...] Die Magyarischen Sagen und Märchen werden dieses Jahr in unserer Sprache erscheinen. Eine begeisterte, schön gestaltete und sorgfältige Arbeit.“ [„,A' szeretre méltó Gróf németül ír, de ír magyarul is, a’ mint ezt két Zsebkönyveinkből tudjuk. Elsőbb versezeteit azoknak dolgozta, úgy mond, a' kik nem értenek magyarul. így a'német Verselés' útjára vezetve, megmaradótt ez mellett. Saját Verseit lefordíthatta volna Nemzete' nyelvére, de azt tiltá szerénysége. Az helyet jobban használá , a' Magyar és egyszersmind a' Német Literatúra' javára, idejét, midőn némelly magyar versezeteinket lefordította németre; [...] A' Magyarok' Regéji és Mesélései még ez idén a' mi nyelvünkön is megjelennek. Lelkes, nagy csinú, nagy gondú dolgozás.“ In: Magyar Kurír [Ungarischer Kurier]. Jg. 39, Nr. 33 (26. April 1825), S. 258-259.

92 Vgl. Ferenc Kazinczy: Könyv-vizsgálat. Gedichte von Grafen Johann Mailáth [Buchbesprechung. Gedichte von Grafen Johann Mailáth]. In: Felső-Magyarországi Minerva [Oberungarische Minerva]. Nr. 4 (1825), S. 158-161.

93 Siehe dazu u.a. Sürgöny [Telegramm]. Jg. 3, Nr. 289 (18. Dezember 1863), Bl. 1r., Forsetz. Nr. 299, Bl. 1 r.

94 „A Grimm testvérek az ő és Gaal gyüjteményéből kezdték ismerni népmeséinket. A népmese e legilletékesb kritikusai hibáztatják ugyan mindkettőjükben a nem épen pontos felfogást és a nem eléggé egyszerü elbeszélést, [...] de mindemellett elég anyagot találnak bennök az összehasonlitásra, a magyar népmese jellemzésére [...].“ In: Koszorú [Kranz]. Nr. 19 (8. November 1863), S. 450-451, hier S. 451.

95 Siehe dazu den Brief 4813 von Toldy an Kazinczy, in dem er die Märchen Mailáths etwas verachtend als „dajkamese“ [Ammenmärchen] bezeichnete. In: János Váczy (Hrsg.): Kazinczy Ferenc összes művei. Harmadik osztály. Levelezés [Sämtliche Werke von Ferenc Kazinczy. Dritte Abteilung. Briefwechsel]. Bd. 20. Budapest: MTA 1910, S. 310. 
96 Siehe dazu Toldys Worte über den Märchensammler Georg Gaal: „Solange man diese als Kleinigkeiten, die bloß für Spinnereien und für das Kinderzimmer geeignet sind, wahrnahm, und als solche waren sie der Aufmerksamkeit eines ernsthaften Mannes unwürdig; man hat noch ihre Bedeutung nicht geahnt, über die sie aus der Sicht der Nation und universell des Menschen verfügen.“ [„Még midőn nálunk ezek egyedül fonódákba s gyermekszobákba illő dibdábnak nézettek, s mint ilyek komoly férfiú figyelmére méltatlanoknak; nem sejtetvén még azon mély jelentőség, melylyel nemzeti, sőt emberi egyetemes tekintetben bírnak."] In: Toldy, Irodalmi arcképei és újabb beszédei, S. 82.

97 Siehe dazu A Kisfaludy-Társaság Évlapjai [Jahresblätter der Kisfaludy-Gesellschaft] 5 (1843), S. 25.

98 Ágnes Kovács: Népmesekutatás [Volksmärchenforschung] (Lexikonartikel). In: Gyula Ortutay (Hrsg.): Magyar néprajzi lexikon [Ungarisches ethnographisches Lexikon]. Bd. 3. Budapest: Akadémiai 1980, S. 741-742.

99 Mariann Domonkos,: Szövegalakítási stratégiák a magyar népmesegyüjtés és -kiadás elméletében és gyakorlatában a 19. században (1848-1872) [Strategien der Textgestaltung in der Theorie und Praxis des Sammelns und und der Veröffentlichung von Volksmärchen im 19. Jahrhundert (1848-1872)]. Dissertation. Budapest: ELTE 2009, S. 32.

100 Siehe dazu die Rezension der Magyarischen Sagen Mailáths in der Theater-Zeitung Bäuerles: „Märchen ist meist ein ausschließendes Eigenthum des Volkes: Sitte, Charakter, Kunst, Poesie und Seele desselben spiegeln sich ganz in dieser Fluth ab, welche auf vaterländischem Boden entspringt [...]“ In: Wiener Theaterzeitung. Jg. 18, Nr. 55 (7. Mai 1825), S. 231-232, hier S. 332.

Open Access. This is an open-access article distributed under the terms of the Creative Commons Attribution 4.0 International License (https://creativecommons.org/licenses/by/4.0), which permits unrestricted use, distribution, and reproduction in any medium, provided the original author and source are credited, a link to the CC License is provided, and changes - if any - are indicated. (SID_1) 